\title{
Monotherapy versus combination therapy in the treatment of benign prostatic hyperplasia: A single center study
}

\begin{abstract}
Background and objectives: Most benign prostatic hyperplasia patients do not present obvious indicators for surgical intervention, so most of these patients are treated initially with medical therapy. This study aimed to compare the incidence of acute urinary retention after treatment with monotherapy with the incidence after combination therapy and determine the need for surgery in both methods.

Methods: This is a retrospective study of the medical records of 248 benign prostatic hyperplasia patients who had attended Rizgary Teaching Hospital from May 2012 to June 2017. These patients were divided into two groups of 138 and 110 patients who have been treated by $0.4 \mathrm{mg}$ tamsulosin capsule once daily and $0.4 \mathrm{mg}$ tamsulosin capsule plus $5 \mathrm{mg}$ finasteride tablet once daily, respectively. Benign prostatic hyperplasia outcomes (acute urinary retention, benign prostatic hyperplasia related surgery) were compared between these two groups according to prostate volume and serum prostate specific antigen.

Results: The combined treatment had significantly reduced the incidence of acute urinary retention and benign prostatic hyperplasia related surgery than monotherapy $(P=0.006$ and 0.044 , respectively). Similarly, when prostate volume and prostate specific antigen were above the cutoff value, both acute urinary retention and benign prostatic hyperplasia related surgery were lower in the combination therapy group than the monotherapy group.

Conclusion: Combined therapy $(0.4 \mathrm{mg}$ tamsulosin plus $5 \mathrm{mg}$ finasteride) was significantly superior to $0.4 \mathrm{mg}$ tamsulosin alone in the reduction of the incidence of acute urinary retention and benign prostatic hyperplasia related surgery among benign prostatic hyperplasia patients.
\end{abstract}

Keywords: Benign prostatic hyperplasia; Acute urinary retention; Benign prostatic hyperplasia related surgery; Prostate volume; Prostate specific antigen.

\section{Introduction}

Benign prostatic hyperplasia (BPH) is the most common older men's urological problem. ${ }^{1}$ Since most patients do not present obvious indicators for surgical intervention, most of these patients are treated initially with medical therapy. ${ }^{2}$ Among the medical therapies used to treat $\mathrm{BPH}$, alpha blockers, and 5 alpha reductase inhibitors were the most efficacious as the $1^{\text {st }}$ line medical therapies. $^{3}$ Previously, no significant differences were reported between monotherapy and combination therapy until the Medical Therapy of Prostatic
Symptoms (MTOPS) study reported that long term treatment of BPH by combination therapy significantly decreases the incidence of acute urinary retention and $\mathrm{BPH}$ related surgeries. ${ }^{4}$ It is indicated by the Medical Therapy of Prostatic Symptoms (MTOPS) study that combination therapy was superior to monotherapy when the prostate volume $(\mathrm{PV})$ was $>40 \mathrm{ml}$ and the serum prostate specific antigen (PSA) concentration was > $4.0 \mathrm{ng} / \mathrm{ml}^{5}$ This study aimed to compare the incidence of acute urinary retention after treatment with monotherapy with the incidence after combination

${ }^{1}$ Rizgari Teaching Hospital, Erbil, I raq.

2 Erbil Teaching Hospital, Erbil, I raq.

* Correspondence: dr.wishyaralbazzaz@gmail.com 
therapy and determine the need for surgery in both methods.

\section{Methods}

A retrospective comparative study of the medical records reported Rizgary Teaching Hospital from May 2012 to June 2017 was carried out. A total of $248 \mathrm{BPH}$ patients treated by medical therapy for at least one year were included in this study. Patients under the age of 50 years had international prostate symptom score of less than or equal to 7 , previously received medical therapy for BPH or combined therapy with anticholinergics, had a history of lower urinary system surgery (BPH related surgery, urinary bladder surgery (urethroplasty, diathermy), patients confirmed to have prostate cancer and $\mathrm{BPH}$, patients who had low urinary flow rate, patients who had lower urinary tract symptoms related to causes other than $\mathrm{BPH}$, and patients lost to be followed up were all excluded from this study. Patients involved in the current study were divided into two groups. The ${ }^{1 s t}$ group, or the monotherapy group, included 138 patients treated by $\alpha$-blockers $(0.4 \mathrm{mg}$ tamsulosin capsule once daily). The $2^{\text {nd }}$ group, or the combination group, included 110 patients treated by a combination of $\alpha$-blockers plus 5 a-reductase inhibitors ( $0.4 \mathrm{mg}$ tamsulosin capsule/5mg finasteride tablet once daily). Incidences of acute urinary retention and BPH-related surgeries were compared between these two groups and between patients classified by PV and serum PSA level. The follow-up period of this study was determined by the onset date of acute urinary retention or BPH-related surgery date in the medical records. All the collected data were entered into a computer using the statistical package for the social sciences (version 23) software. Appropriate statistical tests were performed, Chi-square was used for categorical variables, and Fisher's exact test was used when more than $20 \%$ of the cells of the tables had an expected count of less than 5. The student's t-test was used to compare means. In all statistical analyses, the level of significance ( $P$ value) was set at $\leq 0.05$.

\section{Results}

A total of 248 patients participated in the current study. These patients were divided into 138 patients on the monotherapy group ( $\alpha$ blockers) and 110 patients on the combination therapy group ( $\alpha$ blockers plus 5 - $\alpha$ reductase inhibitors). The mean age of the two groups was significantly different $(65.25 \pm 5.5$ years among the monotherapy group and $67.20 \pm 4.2$ years among the combination therapy group, $P=0.002$ ). The mean follow-up period was significantly longer in combination therapy (37.1 months \pm 6.1 months) than monotherapy ( 33.5 months \pm 5.5 months) with $P$ value of $<0.001$. The $P V$ was 34.20 $\pm 11.8 \mathrm{ml}$ and $35.25 \pm 10.8 \mathrm{ml}$ among the monotherapy and combination therapy groups, respectively $(P=0.471)$. The PSA was $1.8 \pm 1.5 \mathrm{ng} / \mathrm{ml}$ and $1.9 \pm 2.2 \mathrm{ng} / \mathrm{ml}$ among monotherapy and combination therapy groups, respectively $(P=0.672)$. The international prostate symptom score (IPSS) was $25.22 \pm 5.70$ and $23.2 \pm 5.70$ among monotherapy and combination therapy groups, respectively $(P=0.006)$. These details are shown in Table 1.

Table 1: Main characteristics of patients at first reporting.

\begin{tabular}{lccc}
\hline & $\begin{array}{c}\text { Monotherapy (No.=138) } \\
\text { Mean } \pm \text { SD }\end{array}$ & $\begin{array}{c}\text { Combination therapy (No. = 110) } \\
\text { Mean } \pm \text { SD }\end{array}$ & $P$ value \\
\hline Age (years) & $65.25 \pm 5.5$ & $67.20 \pm 4.2$ & 0.002 \\
Follow up (Months) & $33.5 \pm 5.5$ & $37.1 \pm 6.1$ & $<0.001$ \\
PV (ml) & $34.20 \pm 11.8$ & $35.25 \pm 10.8$ & 0.471 \\
PSA (ng/ml) & $1.8 \pm 1.5$ & $1.9 \pm 2.2$ & 0.672 \\
IPSS & $25.22 \pm 5.70$ & $23.2 \pm 5.70$ & 0.006 \\
\hline
\end{tabular}


Significantly, those patients treated by combination therapy have shown a lower incidence of acute urinary retention than those treated by monotherapy with an incidence of $4.5 \%$ and $15.2 \%$, respectively $(P=0.006)$. Similarly, the incidence of $\mathrm{BPH}$ related surgery was lower among combination therapy than monotherapy with an incidence rate of $5.5 \%$ and $13.0 \%$, respectively $(P=0.044)$. The cutoff value of $\mathrm{PV}$ and PSA among acute urinary retention and $\mathrm{BPH}$ related surgeries were $35 \mathrm{ml}$ and $1.9 \mathrm{ng} / \mathrm{ml}$, respectively. The incidence of acute urinary retention when PSA was $\leq$ $1.9 \mathrm{ng} / \mathrm{ml}$ was found to be not significantly different between the monotherapy group $(5.7 \%)$ and the combination therapy group $(2.0 \%)(P=0.312)$. When PSA was more than $1.9 \mathrm{ng} / \mathrm{ml}$, the incidence of acute urinary retention was significantly different $(P<0.001)$ between the two groups $(31.4 \%$ and $6.6 \%$ among monotherapy and combination therapy, respectively. Similarly, the incidence of acute urinary retention when the PV was $\leq 35 \mathrm{ml}$ found to be not significantly different between the monotherapy group (4.3\%) and the combination therapy group $(2.2 \%)$, $P=0.526$. However, the incidence of acute urinary retention was significantly different $(P<0.001)$ when $\mathrm{PV}$ was more than $35 \mathrm{ml}$ (37.8\% and $6.3 \%$ among monotherapy and combination therapy, respectively). The incidence of $\mathrm{BPH}$ related surgeries when PSA was $\leq 1.9 \mathrm{ng} / \mathrm{ml}$ was not significantly different between the monotherapy group (2.3\%) and the combination therapy group (4.1\%), $P=0.554$. However, it was significantly different $(P<0.001)$ when PSA was more than $1.9 \mathrm{ng} / \mathrm{ml}(31.4 \%$ and $6.6 \%$ among monotherapy and combination therapy, respectively). The incidence of BPH related emergencies when the PV was $\leq 35 \mathrm{ml}$ was not significantly different between the monotherapy group $(2.2 \%)$ and the combination therapy group (2.2\%), $P=0.992$. However, it was significantly different $(P=0.001)$ when PV was more than $35 \mathrm{ml}(31.1 \%$ and $7.8 \%$ among monotherapy and combination therapy, respectively). All the above details are shown in Table 2.

Table 2: Incidence of acute urinary retention and BPH related surgeries among monotherapy and combination therapy groups according to prostate specific antigen and prostate volume.

\begin{tabular}{|c|c|c|c|c|c|c|c|}
\hline & & & \multicolumn{2}{|c|}{$\begin{array}{l}\text { Monotherapy } \\
\text { (No.=138) }\end{array}$} & \multicolumn{2}{|c|}{$\begin{array}{c}\text { Combination therapy } \\
\text { (No. = 110) }\end{array}$} & \multirow[b]{2}{*}{$P$ value } \\
\hline & & & No. & $\%$ & No. & $\%$ & \\
\hline \multirow{10}{*}{$\begin{array}{l}\text { Acute Urinary } \\
\text { Retention }\end{array}$} & All & Yes & 21 & 15.2 & 5 & 4.5 & 0.006 \\
\hline & & No & 117 & 84.8 & 105 & 95.5 & \\
\hline & $P S A \leq 1.9$ & Yes & 5 & 5.7 & 1 & 2.0 & 0.312 \\
\hline & & No & 82 & 94.3 & 48 & 98.0 & \\
\hline & PSA $>1.9$ & Yes & 16 & 31.4 & 4 & 6.6 & $<0.001$ \\
\hline & & No & 35 & 68.6 & 57 & 93.4 & \\
\hline & $P V \leq 35$ & Yes & 4 & 4.3 & 1 & 2.2 & 0.526 \\
\hline & & No & 89 & 95.7 & 45 & 97.8 & \\
\hline & $\mathrm{PV}>35$ & Yes & 17 & 37.8 & 4 & 6.3 & $<0.001$ \\
\hline & & No & 28 & 62.2 & 60 & 93.8 & \\
\hline \multirow{10}{*}{$\begin{array}{l}\text { BPH related } \\
\text { surgery }\end{array}$} & All & Yes & 18 & 13.0 & 6 & 5.5 & 0.044 \\
\hline & & No & 120 & 87.0 & 104 & 94.5 & \\
\hline & $\mathrm{PSA} \leq 1.9$ & Yes & 2 & 2.3 & 2 & 4.1 & 0.554 \\
\hline & & No & 85 & 97.7 & 47 & 95.0 & \\
\hline & PSA $>1.9$ & Yes & 16 & 31.4 & 4 & 6.6 & $<0.001$ \\
\hline & & No & 35 & 68.6 & 57 & 93.4 & \\
\hline & $P V \leq 35$ & Yes & 2 & 2.2 & 1 & 2.2 & 0.992 \\
\hline & & No & 91 & 97.8 & 45 & 97.8 & \\
\hline & $\mathrm{PV}>35$ & Yes & 14 & 31.1 & 5 & 7.8 & 0.001 \\
\hline & & No & 31 & 68.9 & 59 & 92.2 & \\
\hline
\end{tabular}




\section{Discussion}

Many men complaining from BPH develops different complications, including acute urinary retention, prostatic hyperplasia related surgeries, urinary incontinence, and urinary tract infection..$^{5-7}$ Many studies have assessed the effects of using a blockers versus combination therapy of $\alpha$ blockers plus $5-\alpha$ reductase inhibitors treatment in improving the $\mathrm{BPH}$ outcomes. ${ }^{1,4-9}$ In the current study, we found that the incidence of acute urinary retention among patients treated with combination therapy $(4.5 \%)$ was significantly less than the incidence $(15.2 \%)$ among patients treated with monotherapy. This result is similar to what was reported by Shin et al. ${ }^{4}$ who found that acute urinary retention incidence is significantly lower in combination therapy $(2.8 \%)$ than monotherapy (13.6\%). Lu Chi-Fong et al. ${ }^{10}$ also found that acute urinary retention incidence is significantly lower in combination therapy (18.2\%) than monotherapy $(38.9 \%)$. In the current study, the incidence of $\mathrm{BPH}$ related surgeries was significantly lower among patients treated by a combined therapy $(5.5 \%)$ than monotherapy $(13 \%)$. This finding is similar to what is reported by Shin et al., ${ }^{6}$ who found that BPH related surgery incidence is significantly lower in combination therapy $(3.2 \%)$ than monotherapy $(8.4 \%)$. Cindolo et al. ${ }^{11}$ also found that the incidence of hospitalization for $\mathrm{BPH}$ related is significantly lower in combination therapy $(4.08 \%)$ than monotherapy $(13.9 \%)$. On the other hand, when PV and PSA are above the cutoff value, both acute urinary retention and BPH related surgery incidence is reduced significantly in combination therapy than monotherapy. This finding is similar to what was reported by Shin et al. ${ }^{6}$ who found that when PV is higher than the cutoff value, the incidence of acute urinary retention and $\mathrm{BPH}$ related surgeries is significantly lower in combination therapy $(4.0 \%$ and $4.7 \%)$ than in monotherapy $(27.0 \%$ and $20.6 \%)$. They also found that when the PSA level is higher than the cutoff value, the incidence of acute urinary retention and $\mathrm{BPH}$ related surgeries is significantly lower in combination therapy (3.8\% for both) than monotherapy $(24.2 \%$ and $17.0 \%)$. Similarly, Roehrborn et al. ${ }^{12}$ reported that the incidence of both acute urinary retention and $\mathrm{BPH}$ related surgeries when PV and PSA above the cutoff value is significantly lower in combined therapy $(4.5 \%$ and $5.1 \%)$ than monotherapy $(14.3 \%$ and $14.0 \%)$.

\section{Conclusion}

The combined therapy of $0.4 \mathrm{mg}$ tamsulosin plus $5 \mathrm{mg}$ finasteride is significantly superior to $0.4 \mathrm{mg}$ tamsulosin alone in reducing the incidence of acute urinary retention and $\mathrm{BPH}$ related surgeries among BPH patients.

\section{Competing interests}

The authors declare no competing interests.

\section{References}

1. Odusanya BO, Tijani $\mathrm{KH}$, Jeje EA, Ogunjimi MA, Ojewola RW. Short-term effect of tamsulosin and finasteride monotherapy and their combination on Nigerian men with benign prostatic hyperplasia. Niger J Surg 2017; 23(1):5-10.

2. Deters LA. Benign Prostatic Hyperplasia $(\mathrm{BPH})$ treatment and management. Jan 2019. (Accessed March 3, 2019, at https:// emedicine.medscape.com/article/437359treatment).

3. Rensing AJ, Kuxhausen A, Vetter J, Strope SA. Differences in the treatment of benign prostatic hyperplasia: Comparing the primary care physician and the urologist. Urol Pract 2017; 4(3):193-9.

4. Shin $\mathrm{TJ}$, Kim $\mathrm{Cl}$, Park $\mathrm{CH}$, Kim BH, Kwon YK. A-blocker monotherapy and $\alpha$-blocker plus 5-alpha-reductase inhibitor combination treatment in benign prostatic hyperplasia; 10 years' long-term results. Korean J Uro 2012; 53(4):248-52.

5. Joo KJ, Sung WS, Park SH, Yang WJ, Kim TH. Comparison of a-blocker monotherapy and a-blocker plus $5 a$-reductase inhibitor combination therapy based on prostate volume for treatment of benign prostatic hyperplasia. J Int Med Res 2012; 40:899-908.

6. Roehrborn CG, Siami P, Barkin J, Damilao R, Walker K, Nandy I, et al. The effects of combination therapy with dutasteride and tamsulosin on clinical outcomes in men with 
symptomatic benign prostatic hyperplasia:4-year results from the Comb AT study. Eur Urol 2010; 57(1):123-31.

7. Roehrborn CG, Siami P, Barkin J, Damilao R, Becher E, Milnana B, et al. The influence of baseline parameters on changes in international prostate symptom score with dutasteride, tamsulosin, and combination therapy among men with symptomatic benign prostatic hyperplasia and an enlarged prostate: 2-year data from the Comb AT study. Eur Urol 2009; 55(2):461-71.

8. Sabbagh AJ, Khalighinezhad M. The survey of effect of combination therapy with tamsulosin finasteride compared with tamsulosin alone on symptom improvement of benign prostatic hypostatic. Immunopathol Persa 2018; 4(2):e20

9. Kang D, Hu C, Fu Y, Wang D. Combination of alpha blocker and 5 alpha reductase inhibitor for treatment of benign prostatic hyperplasia. Clin Invest Med 2017; 40(5):e200-10.

10. Chi-Fong L, Chun-You C, Liang-Ming L, Ke-Hsun L, Yung-Wei L, Chi-Hao H, et al. Do 5a-reductase inhibitors prevent secondary benign prostate hyperplasia-related urinary retention? Urol Sci 2018; 29(2):86-90.

11. Cindolo L, Pirozzi L, Sountoulides P, Fanizza C, Romero M, Castellan $P$, et al. Patient's adherence on pharmacological therapy for benign prostatic hyperplasia (BPH)-associated lower urinary tract symptoms (LUTS) is different: is combination therapy better than monotherapy? BMC Urology 2015; 15:96-102.

12. Roehrborn CG, Barkin J, Siami $P$, Tubaro A, Wilson TH, Morrill BB, et al. Clinical outcomes after combined therapy with dutasteride plus tamsulosin or either monotherapy in men with benign prostatic hyperplasia (BPH) by baseline characteristics: 4-year results from the randomized, double-blind Combination of Avodart and Tamsulosin (CombAT) trial. BJU International 2011; 107:946-54. 